\title{
Tanssi, sisäinen tarina ja sairausnarratiivit
}

\author{
Monitieteisen terveys- ja hyvinvointitutkimuksen dosentti, tanssitaiteen tohtori, tans- \\ sipedagogi, terveystieteiden maisteri (liikuntalä̈̈ketiede) ja fysioterapeutti Hanna \\ Pohjola (hanna.pohjola@uef.fi) työskentelee Koneen Säätiön rahoittamana apuraha- \\ tutkijana ja yliopistontutkijana Itä-Suomen yliopistossa. Pohjolan koulutus-, työ-ja \\ tutkimustaustassa keskeistä on taide ja monitieteisyys, joiden kautta kurotetaan kohti \\ laajempaa ja kokonaisvaltaisempaa näkemystä hyvinvoinnista.
}




\title{
Tanssi, sisäinen tarina ja sairausnarratiivit
}

\author{
Hanna Pohjola
}

Ihminen ankkuroituu elämään kerronnallisuuden kautta erilaisia tarinoita kertoen ja niitä kuunnellen. ${ }^{1}$ Tarinoiden kertominen onkin ikivanha tapa hahmottaa paikkaansa maailmassa ja yhteiskunnassa, joka koostuu laajasta tarinavarannosta: esimerkiksi tarinoina elämänkaaren kulusta tai kulttuurissa vallitsevista säännöistä ja normeista. Tällöin narraatiot jäsentävät samalla yksilön ymmärrystä kulttuurista, mutta myös sitä miten ihminen ymmärtää maailman. Näiden kahden narratiivin, yksityisen ja julkisen, muodostamasta eräänlaisesta dialogista muotoutuu oma ainutlaatuinen suhteensa kerronnallisuuteen: jokaisella on oma (elämäkerrallinen) tarina kerrottavanaan.

Eri taiteenmuodoilla on paikkansa ja merkityksensä kerronnallisuudessa: taiteet erityisesti mahdollistavat luovuuden ja tunteiden ilmaisun, joiden avulla voi kurottautua kohti sitä mikä on aidosti merkityksellistä. Tässä artikkelissa tarkastelen musiikkia ja tanssia ruumiillisena tapana tutkia maailmaa liikkeen kautta elämän murroskohdassa, vakavan sairauden kohdatessa. Lähestyn tanssia ja sen merkitystä sairausnarratiiveissa sisäisen tarinan käsitteen avulla. Tällöin tanssi näyttäytyy yleismaailmallisesti yhteisenä vuorovaikutuksen tasona, joka kietoo yksityiset ja julkiset kertomukset sanattomasti tarinalliseen kiertokulkuun.

1 Latinankielisestä etymologiasta voidaan hahmottaa kerronallisuuden kommunikatiivinen pyrkimys, jossa on subjekti ja objekti: kertoja ja yleisö yhdessä tarinan äärellä. Latinan kielen substantiivi narratio tarkoittaa kertomusta tai selostusta ja narrator kertojaa. Verbi narro tarkoittaa puolestaan kertomista, ilmoittamista, puhumista tai sanomista: englannin kielessä nämä kantasanat ovat muuttuneet substantiiveiksi narrativeja verbiksi narrate (Salmi ja Linkomies 1967, 188; Heikkinen 2007, 142). Suomeksi narraation ja narratiivisuuden voi kääntää kertomukseksi, kerronnallisuudeksi ja tarinallisuudeksi. Usein narraation (ja narratiivin) rinnalla nähdään myös tarinan käsite. Tässä artikkelissa käytän kertomuksen ja tarinan käsitteitä synonyymeinä. 
Sairastuminen tai vammautuminen on usein odottamaton ja yllättävä käännekohta, joka voi muuttaa elämänkulun suuntaa. Sairastuessaan ihminen astuu tai joutuu astumaan hetkeksi sivuun siitä, mitä pidetään niin sanottuna tavallisena elämänä (Frank 1995; Hänninen 1999). Tätä voidaan pitää elämäkerronnallisesti eräänlaisena katkoksena tai käännekohtana elämän polulla. Kun tämä "suunnan menettämisen" kokemus jäsentyy (Frank 1991a; 1991b; 1995), tulee odottamattomasta kokemuksesta jälleen osa elämänpolkua, kertomus kertomusten joukossa.

Tämä sairauskertomus ei kuitenkaan rakennu tyhjiössä, vaan se on suhteessa ympäristöönsä: aikaan, paikkaan ja sosiaalisiin rakenteisiin. Kertomukset siis ikään kuin sopeutuvat ja yhdistyvät kertomusmuotoihin, jotka ovat kulttuurissa saatavilla (Frank 1995, 75). Sosiologi Arthur Frankin (1995) mukaan sairausnarratiivit ilmenevät usein kolmenlaisina kertomisen muotoina: ennalleen palaamis- (engl. restitution), kaaos- (engl. chaos) ja etsintäkerronnallisuutena (engl. quest). Yleisin näistä länsimaisessa yhteiskunnassa on ennalleen palaamisen kertomus (Frank 1995, 85-88; Sparkes 1998, 651), jossa ensisijaisena tavoitteena on palautua sairautta edeltäneeseen tilaan. Kaaoskertomuksen ydin on taas koherenssin puuttuminen ja kausaalittomuus: kaaoskertomusta on vaikea ymmärtää. Etsintäkertomus taas mahdollistaa puolestaan vaihtoehtoisen tavan olla sairas, ja narratiivina se esittää sairastuneen vastuullisena toimijana, joka on kokemuksen todistaja: tällöin kertojan ääni on etualalla (Frank 1995, 115-117).

Huomionarvoista on, että Frankin sairauskertomusmuodot voivat olla paradoksaalisia ja haasteellisia erityisesti vakavasti sairastuneelle: ennalleen toipuminen ei ole välttämättä mahdollista tai sairaus voi olla luonteeltaan etenevää (Frank 1998, 200-201; Thomas-MacLean 2004). Sairastumisen jäsentäminen voi olla myös vaikeaa, jopa mahdotonta, kaoottisessa ja näköalattomassa tilanteessa. Lisäksi sairastunut ei välttämättä löydä kuulijaa kertomukselleen tai hän voi kokea sisäistä ristiriitaa siitä, että henkilökohtaisesti koettu ei sovi valtanarratiiveihin. Myös sairauden aiheuttamat fyysisen toimintakyvyn rajoitukset, kuten esimerkiksi afasia, jonka oireita ovat muiden muassa erilaiset puheen tuottamiseen ja ymmärtämiseen, lukemiseen sekä kirjoittamiseen liittyvät vaikeudet, tuovat haasteita sairausnarratiivin kielelliselle jäsentämiselle. Tällöin taiteet ovat tulkintani mukaan merkittävässä roolissa ei-kielellisinä kokemuksina, jolloin ne mahdollistavat sairauskertomuksen kokemuksellisesti ilman sanoja.

Emeritaprofessori ja sosiaalipsykologi Vilma Hänninen (1999) erottelee kolme kerronnallisuuteen liittyvää käsitettä, jotka ovat vuorovaikutussuh- 
teessa toisiinsa narratiivisen kiertokulun mallissa: sisäinen eli koettu tarina ${ }^{2}$, kertomus eli kerrottu tarina ja draama eli hetkessä tapahtuva toiminnallinen prosessi. Näistä sisäinen tarina näyttäytyy Hännisen $(1999,14,58)$ mukaan elämäntilanteen, -tapahtumien ja -muutosten tulkkina. Painopiste on mielen sisäisessä maailmassa. Tällöin se on ikään kuin sisäinen jäsennetty kokemus, jonka avulla yksilö tulkitsee, paitsi elämänsä tapahtumia, myös situaationsa tarjoamia mahdollisuuksia ja rajoja sosiaalisesta tarinavarannosta omaksumiensa tarinallisten mallien avulla. Kertomus eli kerrottu tarina puolestaan mahdollistuu intersubjektiivisesti. Sisäisen tarinan ytimessä on siis kokijuus, kerrotussa tarinassa puolestaan korostuu kertoja ja yleisö. Tällöin kertomus on ihmisen itsestään toisille kertoma tarina. Draaman käsitteellä Hänninen viittaa itse elävään elämään, toiminnalliseen prosessiin, jossa ihmiset pyrkivät toteuttamaan sisäisessä tarinassaan muodostamia tarinallisia projekteja. (ibid.) Narratiivisen kiertokulun mallissa nämä eri käsitteet ovat toisiinsa suhteessa.

Elämänmurroksissa kuten sairausnarratiiveissa, korostuu tulkintani mukaan tarinan sisäinen merkityksellisyys, joka Hännistä (1999) mukaillen ohjaa ihmisen elämää ja toimintaa ja voi näin lisätä kokijan toimijuutta ja itsepystyvyyttä (ks. lisää esim. Bandura 1995). Sisäisten tarinoiden avulla voidaan tuottaa arvokasta kokemusperäistä ymmärrystä ja tietoa siitä, millaista arki sairauden kanssa on. Tässä kohden sisäisen tarinan käsite lähestyy tarinallista lähestymistapaa kuntoutustyössä (ks. esim. Heikkinen 2007; Hänninen 2021), jossa kuntoutus voidaan nähdä toimintana, joka tukee kuntoutujan pyrkimyksiä luoda arvokkaaksi kokemiaan tarinoita ja toteut-

2 Sisäisen tarinan voi edelleen jakaa kolmeen tasoon. Näistä ensimmäinen viittaa kokemukseen, jossa elämä alun perin näyttäytyy tulkittuna tietyllä tavalla, ikään kuin alustavana tarina. Toisessa tasossa kyseessä on reflektiivinen sisäinen tarina, "itselle kerrottu" ja kielellisesti artikuloitunut muoto. Tällöin esimerkiksi rutiininomaiset merkityksenannot voivat olla ongelmallisia tai vaativat vielä pohdintaa. Kolmas taso on puolestaan metareflektio, jossa tietoisesti eritellään sisäistä tarinaa tietoisena siitä, että se on tarina. (Hänninen 2021) 
taa niitä, vaikka siihen ei ensisijaisesti pyrittäisikään. ${ }^{3}$ Sisäisesti syntynyt ja lopulta kenties jaettu tarina voi tulla myös osaksi laajempaa tarinavarantoa. Kerronnallisuudella ihminen voi saada aikaan siten myös sosiaalisia vaikutuksia, jakaa kokemuksiaan, saada jäsennyksilleen sosiaalista vahvistusta sekä reflektoida kokemustaan. Tällöin kertomus siirtyy sosiaaliseen tarinaja kertomusvarantoon kuulijoiden resurssiksi. Näin ollen tämä intersubjektiivisesti jaetun kertomuksen sosiaalinen vaikutus ei ulotu ainoastaan kertojaan, vaan myös kuulijaan ja mahdollisesti edelleen takaisin kertojaan. (Hänninen 1999, 22, 131) Tästä on tarinallisessa kiertokulussa parhaimmillaan kysymys. Yksilön tason mahdollisten vaikutusten ohella sisäinen tarina jaettuna kertomuksena voi siis tuottaa uudenlaisia sairausnarratiiveja ja luoda uudenlaisen metodisen ja lääketieteellistä kuntoutusta täydentävän tavan lähestyä sairauksia ja niiden hoitoa.

\section{Tanssi ja sisäinen tarina}

Tanssia ja musiikkia pidetään lupaavina lääketieteellistä hoitoa täydentävinä kuntoutusmenetelminä ja niiden vaikutuksia erilaisten sairauksien hoidossa on tutkittu ahkerasti: sekä tanssin että musiikin tutkimusinterventioissa on todettu samankaltaisia fyysisiä, kognitiivisia, sosiaalisia ja psykologisia vaikutuksia osallistujien terveyteen (ks. esim. Fancourt ja Finn 2019; Sheppard ja Broughton 2020; McCrary, Redding ja Altenmüller 2021).

Viime vuosina kiinnostuksen kohteena on ollut erityisesti tanssimisen ja musiikin aikaansaamat neuroplastiset rakenteelliset muutokset aivoissa, sillä tanssiminen ja musiikki yhdessä eivät lisää vain fyysistä toimintakykyä, vaan harjoittavat myös monipuolisesti aivoja. Tällöin muiden muassa muisti, toiminnan suunnittelu, avaruudellinen hahmottamiskyky, mukautuvuus (eli plastisiteetti), neurogeneesi (eli hermosolujen synty) ja keskittymiskyky lisääntyvät (ks. esim. Alpert 2011; Demers ja McKinley 2015; Lossing, Moore ja Zuhl 2017). Jopa tanssimisen katsominen aktivoi aivoissa laajoja alueita

3 Hannu Heikkisen mukaan narratiivisuuden käsitteen voi erityisesti kohdentaa neljään käytännön ulottuvuuteen. Ensinnäkin narratiivin voi nähdä tiedon prosessina, jolloin se orientoituu tietämisen tapaan ja tiedon luonteeseen. Tällöin se on usein liitetty ajatukseen konstruktivistisesta tutkimusotteesta. Toiseksi kerronnallisuus voi kuvata tutkimusaineiston luonnetta, tutkimuksen materiaalia ja aineiston laatua. Se voi olla myös tutkimuksessa aineiston analyysitapa. Lisäksi kerronnallisuutta voi soveltaa narratiivisessa terapiassa. (Heikkinen 2007, 144-152) Tällöin asiakasta voidaan ohjata irrottautumaan vanhasta, ongelmia tuottavasta tarinasta ja luomaan uusi, tyydyttävämpi ja toiveikkuutta herättävämpi sisäinen tarina, jolla esimerkiksi elämäkerronnallinen katkos kuten sairaus voidaan tuoda osaksi elämäntarinaa (Hänninen 1999). 
(ks. esim. Jang ja Pollick 2011). On myös esitetty, että tanssiessa tanssijan ja tanssijoiden välinen aivojen synkroniteetti lisääntyy (Basso, Satyal ja Rugh 2021). Tällöin esimerkiksi kahden tanssijan tanssista tulee jaettu kokemus.

Fyysisen toimintakyvyn ja neuraalisten muutosten ohella tutkimuksellinen mielenkiinto on kohdentunut tanssin sosiaalisiin ja erityisesti (sosiaali) psykologisiin vaikutuksiin: lisääntyneeseen resilienssiin, psykologiseen joustavuuteen, toimijuuteen ja itsepystyvyyteen sekä kohentuneeseen identiteettiin ja itsetuntoon (ks. esim. Bar, Czamanski-Cohen ja Federman 2021; Chappell et al. 2021). Tanssillisen kuntoutuksen etuina on korostettu erityisesti kokonaisvaltaista kokemusta, kehollisuutta, tunnetason ja kognition integraatiota sekä luovaa liikkumista (Matinheikki-Kokko et al. 2016). Samankaltaisia tutkimustuloksia lisääntyneestä toimijuudesta ja itsepystyvyydestä tanssi-interventiossa on raportoitu esimerkiksi masennuksen ja kroonisen kivun kokemisessa ja niiden hoidossa (mm. Shim et al. 2017; Majore-Dusele, Karkou ja Millere 2021). Taustalta löytyy useita psykologisia tekijöitä kuten esimerkiksi tietoisuustaitojen, kehotietoisuuden, itsesäätelyn, hyväksynnän, epämukavuuden sietokyvyn ja rentoutumisen lisääntyminen sekä koettu merkityksellisyys ja luova prosessointi turvallisessa (terapia)ympäristössä (Majore-Dusele, Karkou ja Millere 2021). Tätä psykologista ulottuvuutta on helppo lähestyä ja soveltaa myös sairausnarratiiveissa.

Tutkimusten mukaan tanssimalla voi siis vaikuttaa omaan arkeen, sairauden kokemiseen ja toimintamahdollisuuksiin (Matinheikki-Kokko et al. 2016; Pohjola et al. 2019; Chappell et al. 2021). Tämä on tulkintani mukaan kiinteässä yhteydessä Hännisen (1999) käsitteeseen sisäisestä tarinasta, joka voi olla merkityksellistä erityisesti kahdella tapaa: keinona jäsentää ja tuoda esiin sairauden kokemusta sekä mahdollisuutena suuntautua tulevaisuuteen. Neurotieteen professori Antonio Damasio $(1999,185)$ toteaa, että kehollisen läsnäolon kautta keholliset tuntemukset on mahdollista nostaa tajunnan piirin, sen ei-kielelliseksi sisällöksi. Kun ei-kielellinen kokemus tulee tajuntamme sisällöksi, se voi myös muuntua kielelliseen muotoon. Professori Eeva Anttila $(2009,88)$ täydentää Damasiota mukaillen, että tämä "yhteys kehollisten kokemusten ja kielen muotoon rakentuvien reflektioiden välillä on suora, välitön ja vaivaton. Tanssijoilla näyttäisi olevan erityinen taito tunnistaa ja tulkita kehollisia kokemuksiaan ja antaa niille syvällisiä ja monitasoisia merkityksiä”. Sisäisen tarinankerronnan kannalta tämä on merkittävää, sillä tanssiessa voidaan tuoda läsnä oleviksi ne asiat, joita ei ole halunnut, kyennyt tai voinut kohdata aiemmin. Kyseessä on siis henkilökohtainen kokemus, jolloin ei ole olemassa yhtä ja oikeaa tulkintaa, vaan tulkinta riippuu aina kokijasta. Merkityksellistä on etenkin se, että tanssiessa voimme ikään kuin asuttaa kehomme uudelleen: tutkia mah- 
dollisesti sairauden myötä muuntunutta tai muuttuvaa kehoa kehittyneen kehotietoisuuden avulla. Kokemus fyysisestä toimintakyvyn rajoituksesta voi siis muuttua tanssiessa kokemukseksi kehon kykyisyydestä. (Pohjola et al. 2019.) Esimerkiksi Parkinsonin tautia sairastavien henkilöiden tanssi-interventioissa tanssin on todettu kehittävän, paitsi fyysistä aktiivisuutta, kävelyä ja tasapainoa, myös lisäävän elämänlaatua (ks. esim. Patterson et al. 2018), mutta ennen kaikkea demedikalisoivan: tällöin sairauden mahdollinen leima ja lääketieteellinen hoito eivät määrittele yksilöä, vaan osallistuja on ennen kaikkea ihminen, tanssija (Butt 2017).

Alasdair MacIntyren (1985) mukaan kertomuksia ei kerrota vain retrospektiivisesti, vaan niitä myös eletään. Tällöin ne mahdollisesti suuntaavat tulevaisuutta. Esimerkiksi psykologiassa ajatus ihmisestä tulevaisuuteen suuntautuvana toimijana pikemmin kuin menneisyytensä ohjaamana olentona on viime vuosikymmeninä vahvistunut. Tulevaisuuden visioiden tutkimuksessa kiinnostus ei usein ole niinkään tulevaisuudessa ja sen ennustamisessa, vaan siinä miten tulevaisuutta koskevat näyt ovat läsnä nykyhetkessä: tällöin ne voivat suunnata toimintaa, motivoida ja herättää toivoa. (Hänninen et al. 2021, 133) Näin ollen tanssijan kokema ja tuottama sisäinen tarina voi muuttua ja muuntaa, antaa suunnan elämälle. Tanssimisen kautta mahdollistuva sisäinen tarina kyseenalaistaa tarinallisen ajankulun sekä position ja näin jakaa viime vuosikymmenen aikana eri alojen tutkijoiden kiinnostuksen tulevaisuuden tutkimiseen. Anttilaa (2009, 88) mukaillen tanssiessa "yksittäinen havainto tai tuntemus saattaa laukaista assosiatiivisen ketjun, jossa mennyt, nykyinen ja tuleva liittyvät yhteen ja jossa inhimillisen olemassaolon monet kysymykset kietoutuvat monisäikeiseksi merkitysyhteyksiksi”. Tanssin moniaistisuus juurruttaa tähän hetkeen, mutta mahdollistaa ajassa ja situaatiossa liikkumisen luovalla tavalla. Tarinoiden maailma on siis myös mahdollisuuksien maailma.

Damasion mainitsema ei-kielellisen tasolla tapahtuva kehollinen läsnäolo tanssiessa voi mahdollistaa myös niin sanottujen rikkoutuneiden narratiivien kokemisen ja myöhemmin myös niiden kertomisen. Nämä rikkoutuneet narratiivit ovat yleisiä etenkin sairausnarratiiveissa, jos sairaus vaikuttaa esimerkiksi kognitiiviseen tai motoriseen toimintakykyyn (Hydén ja Brockmeier 2008; Pohjola 2020). Tällöin tanssimisen ytimessä ei ole "juonellistettu" ja koherentti tarina, vaan aistiminen ja kokemuksellisuus. Sisäistä tarinaansa tanssivan ei silloin tarvitse täyttää mitään ulkoisia raameja, vaan voi ja saa olla itselleen rehellinen: kokea ja tuntea sen mikä kyseisessä hetkessä on tärkeää. Kokemukseni mukaan tässä sisäisen tarinan hetkessä on läsnä myös ääretön ja sanaton: taiteen kosketus pyhyyteen ja paradoksit, jotka vapauttavat. Tässä ohikiitävässä hetkessä soittajasta tulee 
musiikki, tanssijasta tulee tanssi. Ei ole eroa näkyvän ja näkymättömän välillä. Kokemus ylittää sanat ja ulottuu sinne, minne sanat eivät voi yltää.

\section{Tanssin merkitystodellisuus ja yhdessä jaetut sisäiset tarinat}

Taiteet (kuten esimerkiksi musiikki ja tanssi tässä artikkelissa) ovat esteettisiä kokemuksia, jotka "asuvat" kehossa tällä Damasion mainitsemalla pre-reflektiivisellä tietoisuuden tasolla. Esimerkiksi aivotutkija ja psykologian professori Lauri Nummenmaa on osoittanut useissa tutkimuksissaan tunteiden kehollisuuden (ks. esim. Nummenmaa et al. 2014). Nummenmaa toteaa, että "taide tuntuu kehossa voimakkaasti. Taiteen herättämät tunteet tuntuvat kehossa kuten muutkin tunteet. Kun taide herättää pelkoa, vihaa, inhoa, liikutusta, hämmennystä tai koskettavuutta, kullakin tunteella on oma paikkansa kehon tunnekartassa” (Peltonen 2021). Kun taiteen kontaktipintana ovat omat kehollistuneet elämänkokemukset ja tunteet, on kyseessä mielestäni syvä ja rikas merkitystodellisuus, jolla on yleismaailmallinen resonanssi. Narratiivisessa viitekehyksessä tanssin voikin tulkita olevan universaali kieli, joka mahdollistaa yhteyden itseemme ja toisiimme, sanattomasti. Tanssimisen avulla ihmiset kertovat tarinoita itselleen ja toisilleen: tanssiva keho on ennen kaikkea tarinankertoja. Etelä-afrikkalainen tanssitaiteilija ja näyttelijä Gregory Vuyani Maqoma (Tanssin tiedotuskeskus 2020) kiteyttää vuoden 2020 tanssinpäiväjulistuksessaan oivallisesti, mistä tässä tanssin mahdollistamassa ontologisessa yhteydessä on kyse: "Kun tanssimme kehoillamme, liikehdimme tilassa ja kosketamme toisiamme, syntyy liikettä luovien sydänten voimaa. Se koskettaa sieluja ja välittää parantavaa energiaa, jolle on huutava tarve kaikkialla”.

Tanssiessa voi ja saa asettua rehellisesti kokemuksensa äärelle hyväksyvästi ja kunnioittavasti. Tanssi sallii ajatukset, tunteet ja toiminnan kehon kautta. Se lisää tunneälyä, kehontuntemusta ja kehotietoisuutta sekä mahdollistaa pysähtymisen olemisen äärelle, jossa saa ja voi olla kokonainen ja keskeneräinen. Tanssi on itsessä ja toisessa olevan erityisyyden kunnioittamista, se on silta itseen ja toiseen, inhimillisyyden lähteelle. Tanssi koettuna taidemuotona herättää elämään kaikilla aisteilla. Tanssissa on leikin hulluttelun mahdollisuus, ja siinä voi kokea sekä jakaa harmaanraskaat tunteet, kun sanoja ei ole tai sanoilla ei kokemukseen asti voi kurottaa. Tanssiessa olemme lohdullisesti yksin ja yhdessä. (Pohjola 2019.) Itselleni tanssi mahdollistaakin juuri syvimmän dialogin ja kosketuksen omaan olemisen tapaani jäsentää maailmaa itsessäni ja ympärilläni. Tanssin sisältämä liike on ainutlaatuinen ja alati muuttuva olemukseltaan; ajattomuuden 
värittämässä hetkessä se on kaikkien aistien riemuvoitto. Se on kuin seitin ohuen ohutta verkkoa, joka rikkoutuu helposti ja katoaa palaamatta entiselleen. Koti, jossa ruumis ja mieli ovat yhtä. (Pohjola 2012, 9.)

\section{Lähteet}

Alpert, Patricia. 2011. "The Health Benefits of Dance". Home Health Care Management E Practice 23 (2): 155-157. https://doi.org/10.1177/1084822310384689.

Anttila, Eeva. 2009. ”Mitä tanssija tietää? Kehollinen tieto ajattelun ja oppimisen perustana". Aikuiskasvatus 29 (2): 84-92.

Bandura, Albert. 1995. Self-efficacy in changing societies. Cambridge: Cambridge University Press.

Bar, Anat, Johanna Czamanski-Cohen ja Judith Dita Federman. 2021. ”I Feel Like I Am Flying and Full of Life: Contemporary Dance for Parkinson's Patients". Frontiers in Psychology 12. https://doi.org/10.3389/fpsyg. 2021.623721

Basso, Julia, Medha Satyal ja Rachel Rugh. 2021. "Dance on the Brain: Enhancing Intra- and Inter-Brain Synchrony". Frontiers in Human Neuroscience 14. https://doi. org/10.3389/fnhum.2020.584312

Butt, Carrie. 2017. "Move Your Arm Like a Swan: Dance for PD Demedicalizes Parkinson Disease". JAMA 317 (4): 342-343. https://doi.org/10.1001/jama.2016.21033

Chappell, Kerry, Emma Redding, Ursula Crickmay, Rebecca Stancliffe, Veronica Jobbins ja Sue Smith. 2021. "The aesthetic, artistic and creative contributions of dance for health and wellbeing across the lifecourse: a systematic review". International Journal of Qualitative Studies on Health and Well-being 16(1). https://doi.org/10.1080/17482631.2021.1 950891

Damasio, Antonia. 1999. The feeling of what happens: Body and emotion in the making of consciousness. New York: Harcourt Brace \& Company.

Demers, Marika ja Patricia McKinley. 2015. "Feasibility of Delivering a Dance Intervention for SubAcute Stroke in a Rehabilitation Hospital Setting". International Journal of Environmental Research and Public Health 12 (3): 3120-3132. https://doi.org/10.3390/ ijerph120303120

Fancourt, Daisy ja Saoirse Finn. 2019. "What is the evidence on the role of the arts in improving health and well-being? A scoping review". WHO Regional Office for Europe, Health Evidence Network (HEN) synthesis report 67. Tark. 25.10.2021. https://apps.who. int/iris/bitstream/handle/10665/329834/9789289054553-eng.pdf.

Frank, Arthur. 1991a. At the Will of the Body. Reflections on Illness. Boston: Houghton Mifflin.

Frank, Arthur. 1991b. "For Sociology of the Body. An Analytical Review". Teoksessa 
The Body. Social Process and Cultural Theory, toim. Mike Featherstone, Mike Hepworth ja Bryan Turner, 36-102. London: Sage.

Frank, Arthur. 1995. The Wounded Storyteller. Body, Illness and Ethics. Chicago: The University of Chicago.

Frank, Arthur. 1998. "Just listening. Narrative and deep illness". Families, Systems, E Health 16(3), 197-212. https://doi.org/10.1037/h0089849

Heikkinen, Hannu. 2007. "Narratiivinen tutkimus - todellisuus kertomuksena". Teoksessa Juhani Aaltola ja Raine Valli (toim.): Ikkunoita tutkimusmetodeihin II: Näkökulmia aloittelevalle tutkijalle tutkimuksen teoreettisiin lähtökohtiin ja analyysimenetelmiin, 142-158. Jyväskylä: PS-kustannus.

Hydén, Lars-Christer ja Jens Brockmeier. 2008. Health, illness and culture: broken narratives. New York: Routledge.

Hänninen, Vilma. 1999. Sisäinen tarina, elämä ja muutos. Väitöskirja. Acta Universitatis Tamperesis 696. Tampereen yliopisto; Tampere.

Hänninen, Vilma. 2021. "Minuus ja elämänkulku. Sisäinen tarina, elämä ja muutos”. Tark. 25.10.2021. https://www.studocu.com/fi/document/ita-suomen-yliopisto/minuus-ja-elamankulku/mie-hanninen-tiivistelma-sisainen-tarina-elama-ja-muutos/5673909.

Hänninen, Vilma, Hanna Pohjola, Merja Tarvainen, Johanna Hätilä, Heidi Korhonen, Helena Rovamo ja Anneke Sools. 2021. "Kirje tulevaisuudesta -menetelmä”. Teoksessa Sanna Ryynänen ja Anni Rannikko (toim.): Tutkiva mielikuvitus. Luovat, osallistuvat ja toiminnalliset tutkimusmenetelmät yhteiskuntatieteissä, 132-153. Helsinki: Gaudeamus.

Jang, Seon Hee ja Frank E. Pollick. 2011. "Experience Influences Brain Mechanisms of Watching Dance". Dance Research: The Journal of the Society for Dance Research 29, 352-377. http://www.jstor.org/stable/dancresejsocidan.29.352.

Lossing, Ana, Mary Moore ja Micah Zuhl. 2017. "Dance as a treatment for neurological disorders". Body, Movement and Dance in Psychotherapy 12 (3): 170-184. https://doi.org/1 $\underline{0.1080 / 17432979.2016 .1260055 .}$

Majore-Dusele Indra, Vicky Karkou ja Inga Millere. 2021. ”The Development of Mindful-Based Dance Movement Therapy Intervention for Chronic Pain: A Pilot Study With Chronic Headache Patients". Frontiers in Psychology 12. https://doi.org/10.3389/fpsyg. 2021.587923.

Matinheikki-Kokko, Kaija, Ulla Härkönen, Minna Muhonen ja Salla Sipari. 2016. "Tanssi- ja liiketerapia kuntoutusmuotona: Kuntoutuksen vaikutukset ja hyödyt kirjallisuuskatsauksen, asiakaskokemusten ja ammattilaisten kokemusten valossa”. Kela, Työpapereita 99. Tark. 25.10.2021. https://helda.helsinki.fi/bitstream/handle/10138/164471/ Tyopapereita99.pdf?sequence=1.

MacIntyre, Alasdair. 1985. After Virtue: A Study on Moral Theory. London: Duckworth.

McCrary Matt, Emma Redding ja Eckart Altenmüller. 2021. "Performing arts as a health resource? An umbrella review of the health impacts of music and dance participation”. PLoS ONE 16(6): e0252956. https://doi.org/10.1371/journal.pone.0252956. 
Nummenmaa Lauri, Enrico Glerean, Riitta Hari ja Jari K. Hietanen. 2014. "Bodily maps of emotions". Proceedings of the National Academy of Sciences 111 (2): 646-651. https:// doi.org/ 10.1073/pnas.1321664111.

Patterson, Kara, Jennifer Wong, Eric Prout ja Dina Brooks. 2018. "Dance for the rehabilitation of balance and gait in adults with neurological conditions other than Parkinson's disease: A systematic review". Heliyon 4 (3):e00584. https://doi.org/10.1016/j. heliyon.2018.e00584.

Peltonen, Leeni. 2021. "Kuukauden vieras Lauri Nummenmaa: Taide herättää eloon koko tunnekartan”. Tark. 25.10.2021. https://ateneum.fi/kuukauden-vieras/lauri-nummenmaa-taide-herattaa-eloon-koko-tunnekartan/.

Pohjola, Hanna. 2012. Toinen iho. Uransa loukkaantumiseen päättäneen nykytanssijan identiteetti. Väitöskirja. Acta Scenica 29. Teatterikorkeakoulu, Helsinki.

Pohjola, Hanna, Paavo Vartiainen, Pasi Karjalainen ja Vilma Hänninen. 2019. "The potential of dance art in the recovery from a stroke: a case study". Nordic Journal of Dance 10 (1+2): 32-43. https://www.nordicjournalofdance.com/volume10(1+2).html.

Pohjola, Hanna. 2019. "Tanssiminen neurologisen kuntoutuksen tukena”. Liitos (3): 22-23.

Pohjola, Hanna. 2020. "Acquired disability in young women: a challenge for identity?". Journal of Youth Studies 23 (2): 127-139. https://doi.org/10.1080/13676261.2018.1529 $\underline{864}$.

Salmi, J.W ja Edwin Linkomies. 1976. Latinalais-suomalainen sanakirja. Helsinki: Otava. Sheppard, Alexa ja Mary Broughton. 2020. "Promoting wellbeing and health through active participation in music and dance: a systematic review". International Journal of Qualitative Studies on Health and Well-being 15(1). https://doi.org/10.1080/17482631.2020.1 732526.

Shim, Minjung, R. Burke Johnson, Susan Gasson, Sherry Goodill, Richard Jermyn ja Joke Bradt. 2017. "A Model of Dance/Movement Therapy for Resilience-Building in People Living with Chronic Pain”. European Journal of Integrative Medicine. 9: 27-40. https://doi.org/10.1016/j.eujim.2017.01.011.

Sparkes, Andrew. 1998. "Athletic identity. An Achilles' heel to the survival of self". Qualitative Health Research 8:5, 644-664. https://doi.org/10.1177/104973239800800506.

Tanssin tiedotuskeskus. 2020. "Kansainvälisen tanssin päivän julistus 2020". Tark. 2.12.2020. https://www.danceinfo.fi/ilmoitustaulu/kansainvalisen-tanssin-paivan-julistus-2020/.

Thomas-MacLean, Roanne. 2004. "Understanding breast cancer stories via Frank's narrative types". Social Science and Medicine 58(9), 1647-1657. https://doi.org/10.1016/ S0277-9536(03)00372-1. 